\title{
KITESURFING - A UNIQUE MOVEMENT EXPERIENCE
}

\author{
Valeria BĂLAN ${ }^{1}$, Vlad DRAGOMIRESCU ${ }^{1}$, Marius GHIAȚA $\breve{a}^{2}$, \\ Carmen Luminița ONOIU ${ }^{3}$, Camelia BRANET ${ }^{4}$ \\ ${ }^{1}$ National University of Physical Education and Sport, Faculty of Physical Education and Sport, Bucharest, \\ Romania \\ 2 "Mircea Sântimbreanu" Secondary School, Bucharest, Romania \\ 3 “Emil Racoviță” National College, Bucharest, Romania \\ ${ }^{4}$ Politehnica University of Bucharest, Sport Department, Romania \\ *Corresponding author: valiswim@yahoo.com
}

https://doi.org/10.35189/dpeskj.2021.60.1.4

\begin{abstract}
The desire of people of different ages to spend more and more time in nature and maximally benefit from the resources in the natural environment is one of the current trends in leisure activities. The extensive use of high-performance equipment and technologies makes it possible to live unique movement experiences that associate mobility with adrenaline, intense emotions with overcoming one's limits. This trend also incorporates the practice of extreme sports, which have considerably developed due to the constant emergence of new disciplines that satisfy increasingly eccentric tastes. The tendency to practise extreme sports is noticed among young people but also among adults and seniors. Obviously, the extreme sport practised is different, adults and seniors being more reluctant. A category of sports whose popularity has grown in recent years is that of extreme water sports, which include kitesurfing or kiteboarding. This sport uses a kite, a control system and a board to ride on water. They are set in motion by both the power of the wind and the abilities of the kiteboarder, who needs to know the rules to correctly use the equipment. Although kitesurfing seems to be a sport accessible to all ages and training levels, it requires good fitness as well as a proper understanding of the equipment and environmental factors, which definitely influence its practice. Kitesurfing offers participants the opportunity to become aware of their own limits and to combine sport and passion during a unique movement experience that cannot be achieved by practising another sport.
\end{abstract}

Keywords: extreme sport, kitesurfing, equipment, learning.

\section{Introduction}

The desire of people of different ages to spend more and more time in nature and maximally benefit from the resources in the natural environment (Fadda, 2019) is one of the current trends in leisure activities. The extensive use of high-performance equipment and technologies makes it possible to live unique movement experiences that associate mobility with adrenaline, intense emotions with overcoming one's limits, the participant feeling free, unconstrained by anything (Știrbu \& Știrbu, 2014).

This trend also incorporates the practice of extreme sports (Keane et al., 2020), which have considerably developed due to the constant emergence of new disciplines that satisfy increasingly eccentric tastes. At the same time, modern technology enables the design of increasingly safe protective equipment that allows even the more reluctant people to enjoy the pleasure of practising these sports.

The emergence of extreme sports in which the risk is moderate has led to an increase in the number of participants. The desire to practise such leisure sports is also noticed among young people, who want to take risks, challenge danger and go beyond their own limits (Știrbu \& 
Știrbu, 2014). Moreover, young people want to leave behind their daily routines and comfort zones, thus finding various activities able to satisfy their need for adrenaline. They also want to keep up with everything that is new and not to be outdone by their friends, which is why they accept major challenges that often endanger their lives.

The number of adults practising extreme sports is also growing. Obviously, their taste for practising certain sports is different from that of young people (Fruehauf et al., 2020) because adults are more reluctant but have the same desire to face difficult challenges. We should not forget that the number of women who practise or want to try various extreme sports is increasing (Știrbu \& Știrbu, 2014). At the same time, disabled people want to try extreme sports but differentiated instruction (Marinescu et al., 2014) and specific adaptation should be applied.

At this point, it is worth mentioning the pleasure or curiosity of watching extreme athletes during both sports competitions broadcast on TV or online and live competitions taking place in the natural environment, for example, the first stage of the 2017 World Kitesurfing Cup brought together over 150,000 spectators on the beach throughout the week (Ultimate France, 2018), as well as the tendency of older people to practise extreme sports (Immonen et al., 2018; Baumbach et al., 2018).

\section{Current state of knowledge reflected in the literature}

Extreme sports, also known as action sports (Duong, 2014), adventure sports (Brymer \& Feletti, 2020; Duong, 2014; Brymer et al., 2009), alternative sports or lifestyle sports (Duong, 2014), associate a high level of risk or danger (Duong, 2014) with very good motor abilities and skills (Forsyth et al., 2020). These non-traditional sports involve extreme height, great speed, a high level of physical exertion and highly specialised equipment (Cho et al., 2010).

The literature does not present a unitary perspective on the classification of extreme sports. A first point of view (Tomlinson \& Leigh, 2004) divides extreme sports into three main categories: air sports, land sports and water sports. Another point of view (Fandom, 2018) classifies extreme sports into: popular sports that may have some extreme elements, such as extreme skiing, mountain biking or white-water kayaking, and sports that combine motor abilities and skills from two or more sports, such as snowboarding (combining skateboarding and surfing) or skysurfing (combining skydiving and snowboarding). There are also individual extreme sports that can be competitive or non-competitive (snowboarding, bungee jumping, skysurfing) and extreme team sports that are not competitive, their stated purpose being adventure (rafting) (Fandom, 2018). Another point of view (Știrbu \& Știrbu, 2014) is shown in Table 1 and divides extreme sports into several categories:

Table 1. Classification of extreme sports

\begin{tabular}{|c|c|c|c|c|}
\hline Extreme air sports & $\begin{array}{l}\text { Extreme snow (winter) } \\
\text { sports }\end{array}$ & Extreme water sports & Extreme land sports & $\begin{array}{l}\text { Extreme wheel } \\
\text { sports }\end{array}$ \\
\hline Parasailing & Skiing & Canyoning & Adventure racing & Longboarding \\
\hline Skydiving & Snowboarding & Surfing & Rock climbing & Freeline skating \\
\hline Hang gliding & Snow skating & Kayaking & Hacky sack & Flowboarding \\
\hline Paragliding & Skimboarding & Kitesurfing & Flybar & Waveboarding \\
\hline Parachuting & Bobsleigh & Rafting & Powerbocking & Rollerboarding \\
\hline Rappelling & Luge & Scuba diving & Kiiking & Skateboarding \\
\hline Climbing & Snow biking & Windsurfing & Zorbing - Parkour & \\
\hline
\end{tabular}




\begin{tabular}{|c|c|c|c|}
\hline Bungee jumping & Snowblading & $\begin{array}{c}\text { Snorkelling } \\
\text { Water skiing } \\
\text { Wakeboarding } \\
\text { Yachting } \\
\text { Cave diving } \\
\text { Powerboating }\end{array}$ & $\begin{array}{c}\text { Freestyle } \\
\text { motocross } \\
\text { a.k.a. FMX } \\
\text { Mountain biking }\end{array}$ \\
\hline
\end{tabular}

\section{General issues}

Extreme water sports are individual or collective sports practised in the aquatic environment with the help of highly specialised protective equipment (Ultimate France, 2018) whose use needs long training (Știrbu \& Știrbu, 2014; Ultimate France, 2018) to reduce minor and major risks. These sports require intense physical exertion based on very good physical and mental training as well as good health. Moreover, they give participants enough adrenaline but also help them achieve superior performance and fulfil their desire to exceed their own limits.

This category of extreme water sports includes kitesurfing, which combines motor skills specific to several water sports such as surfing, windsurfing and wakeboarding (Bourgois et al., 2014).

Kitesurfing uses a kite, a control system and a board to ride on water. They are set in motion by both the power of the wind (Nebas \& Heller, 2014; van Bergen et al., 2016) and the abilities of the kiteboarder, who needs to know the rules to correctly use the equipment.

Kitesurfing has gradually become a sport that attracts more and more male but also female participants. Due to its popularity (Petersen et al., 2002; Grzeczka et al., 2016; Morvan et al., 2018), there has been a transition from the area of leisure sports to that of competitive sports, which has increasingly developed and expressed its Olympic aspirations (Kupciw \& MacGregor, 2012). As we did not intend to address the competitive aspects of kitesurfing, we would like to mention only the absolute sailing speed record set by the French kitesurfer Alex Caizergues on 4 October 2008, which is $50.57 \mathrm{knots}(93.66 \mathrm{~km} / \mathrm{h})$. This speed has been validated by the World Sailing Speed Record Council (WSSRC) and certifies that kitesurfing is the fastest way of sailing. When practised as a leisure activity, the sailing speed is lower (up to $35 \mathrm{knots}=64.82 \mathrm{~km} / \mathrm{h}$ ) (Bourgois et al., 2014. Leeuwerke et al., 2016) and depends on the wind speed, the size of the kite and the state of the water surface (Caraballo et al., 2021). The sailor can perform jumps up to 15 meters high and 30 meters long while doing different manoeuvres or stunts in the air (Bourgois et al., 2014) or can glide quietly and return to the water surface to go on sailing.

\section{Topic Addressed}

Appeared in the late 1990s, kitesurfing is considered a fairly new sport but which has always attracted many participants, thus becoming very popular (Castro Maqueda et al., 2020) in a relatively short period of time (Kupciw \& MacGregor, 2012).

However, there are some (Currer, 2002) who claim that this sport is not a new one. Their opinion is argued by the fact that the kite was used as a means of propulsion in China as far back as the 13th century (White Cap Windsurfing, 2020). In addition, the large-sized kite was used to move boats on water but also some carriages on dry land - Bristol, in 1826 (Gratwick, 
2015), in an attempt to find a means of transport without the help of horses. To facilitate this action, the kite was controlled using a four-line system, which is still common today.

After 1960, flight enthusiasts and sport lovers tried to design a kite that could help people move faster. Therefore, they combined the kite with various materials specific to some winter sports (ice skates, skis) or summer sports (roller skates, canoes, water skis, surfboards, parachutes, paragliders, etc.).

At the same time, new textile materials were created or taken over and adapted in order to manufacture kites; those materials were malleable but durable and allowed the design of an inflatable kite that could also be adapted for kitesurfing.

An important moment in the history of this sport was the invention (patented in 1984) of two French brothers, Bruno and Dominique Legaignoux, who designed a special kite for kitesurfing (Currer, 2002; Gratwick, 2015). Subsequently, the Legaignoux brothers perfected their kite (Currer, 2002; Gratwick, 2015) and obtained a pre-formed structure of inflatable tubes and a simple system of lines attached to the wing tips, which were very useful to relaunch it on water. The kite has continuously been improved, and nowadays it is bow-shaped (Hapgood, 2014), being easier to handle and better adapted to the specific requirements of kitesurfing. Obviously, there are currently several types of kites, each one with its advantages and disadvantages. What matters is their ability to generate sufficient traction so that they can be easily controlled by the kitesurfer. When choosing a kite, other factors should also be taken into account, for instance: the ease with which the kite can be relaunched when it is in the water, the upwind sailing performance, the ability to handle jumps and the levels of control over the kite's power (Hapgood, 2014).

An essential role in the dynamics of kitesurfing is played by the lines used to handle the kite. In modern kitesurfing, four or five lines are used (White Cap Windsurfing, 2020). Here again, the quality of the material of which they are made is important because the lines have to be durable over time, withstand high stresses and float on the water surface (Currer, 2002). If a four-line kite is used, the minimum strength of the main lines should be equal to 2.5 times the kiteboarder's bodyweight, while the important brake lines should have strength equal to the user's bodyweight (Clayton, 2016). The most commonly used line lengths are between 20 and 25 meters (Gratwick, 2015) up to 30 meters (White Cap Windsurfing, 2020) or 40 meters (Clayton, 2016) and should always take into account the size of the kite and the wind. It is believed that shorter lines are suitable for better trained participants (Currer, 2002), while longer lines are recommended for beginners. However, shorter lines reduce the kite's power but increase its speed, and when longer lines are used, the kite has more power from the wind but sailing becomes slower (Currer, 2002).

The kite is controlled with the help of special equipment (Clayton, 2016) that depends on the type of kite used. In most cases, the equipment consists of a four-line control bar but kiteboarders can also use a pair of handles to control the lines. By means of this control device, participants can manoeuvre the kite and steer it in any direction (they can swing the kite to the left by pulling the left end of the bar, and a vice-versa action will result in swinging it right; if the bar is horizontal or in a neutral position, the kite will continue down its current flight path). This device must also be equipped with a highly reliable "push-away - quick release system" that should be easy to control and allow the participant to detach the kite in emergency situations. When this system is used, the kite should remain attached to the release line without 
exerting traction force. The kite is still connected to the athlete by the "safety leash", which in turn has a safety system that acts if the kite attached to the release line goes on exerting traction force. Once this last safety system has been activated, the kite is no longer attached to the athlete, who will get back to shore by swimming.

However, kitesurfing equipment is not limited to a kite and its control system. Riding on water involves using a sports material that has changed and evolved as the kite has been improved. Initially, participants used water skis. In the late 1990s, the two skis were replaced by a single unidirectional board similar to the surfing or windsurfing one (Gratwick, 2015). It is thinner than the surfing board, has sharp edges, and its length is $140-230 \mathrm{~cm}$. The unidirectional board is suitable for those who want to sail at higher speeds, but also when the wind is light. Given that the unidirectional board is long, it is much more difficult to control when the wind is strong (Hapgood, 2014). However, this type of board is still used quite a lot because using a fast kite together with the unidirectional board on choppy waters or wavy waters allows riding the waves like in surfing.

At the beginning of the 21st century, the bidirectional board appeared and has become very popular (Gratwick, 2015) because it has greater reliability and allows the participant to have more freedom of movement. This board, also known as the twin-tip board, is very thin and is ideal for tricks (jumps, airborne turns, etc.).

Kitesurfing equipment is complemented by protective equipment (Clayton, 2016). The athlete wears a neoprene wetsuit (its thickness depends on the water temperature) and life jacket. If the water temperature or weather conditions require it, the kitesurfer can wear neoprene gloves and shoes. Beginners should use a thicker wetsuit than advanced athletes because they stay longer in the water. Helmets should be worn especially in strong wind conditions to protect the kiteboarder's head area. An important component of the equipment is the harness system, which is attached to the control device. Its role is to reduce tension and facilitate the control of the kite because it permanently exerts very high tension on the athlete's arms. Kitesurfers should wear special water shoes to prevent any unwanted injuries that may be caused by the underwater rocks that cannot be seen.

But not only the equipment is important in kitesurfing. An aspect that should be paid the utmost attention refers to learning specific motor skills. Obviously, the learning process has particular features and involves several stages that can be completed during a different number of hours (Figure 1) (Mexican Caribbean Kitesurf, 2017). Some of the stages take place on dry land so that the participant can learn to handle and control the kite but also learn wind-related notions, while the other stages take place in the water environment. 


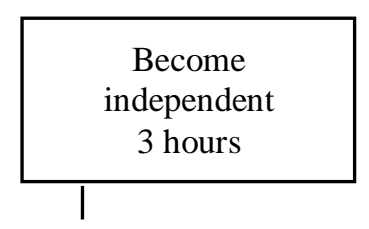

\section{2. transitions}

11. ride upwind

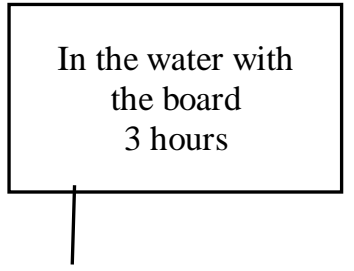

8. assisted water start

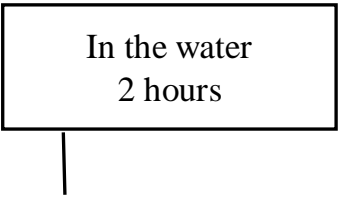

7. power stroke

6. body drag upwind

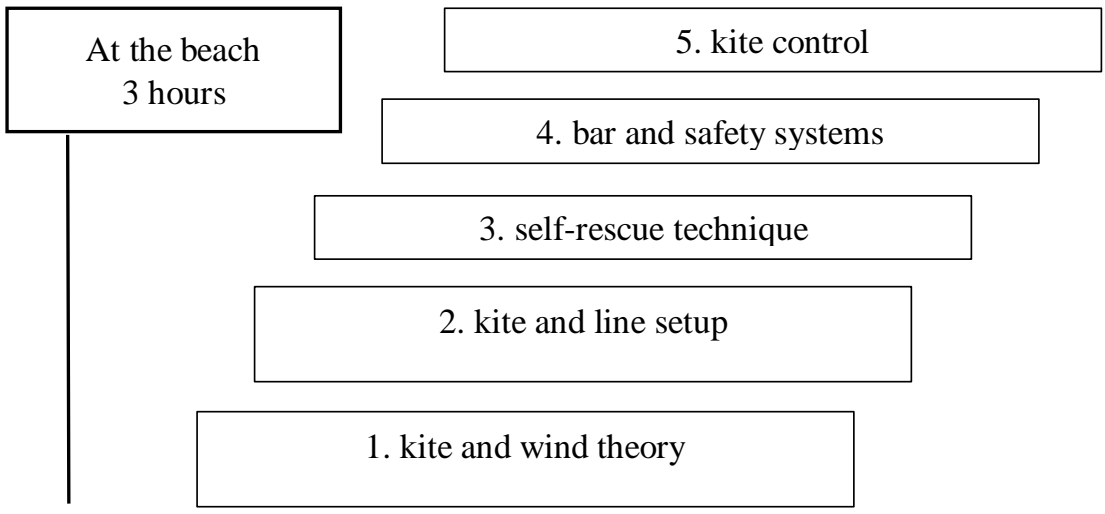

Figure 1. Stages of learning motor skills specific to kitesurfing

Before starting to learn, the participant should be informed about the high risks associated with the practice of this sport (Exadaktylos et al., 2005; Currer, 2002); at the same time, the learner's level of fitness and ability to swim should be assessed.

We mention that the presentation of the kitesurfing learning stages combines the description made by specialists with the practical experience of some fans of this sport from our country:

1. kite and wind theory - this is an important stage because the learner comes into contact with the kite for the first time and finds out how it works in wind conditions. This stage should take place in an open area, preferably on a beach area where no other activity is performed and where there is no injury risk either for the learner or other people. The participant should learn to recognise the direction from which the wind is blowing and the wind direction relative to the shore and should also understand how wind gusts manifest themselves;

2. kite and line setup - the participant learns how to inflate the kite and how to tie the lines properly because their correct preparation is an essential step for lifting the kite in the air; beginners start with two lines and a kite of 2-3 square metres (Currer, 2002), and later a larger kite can be used but this depends on each one's level of fitness and technical ability to handle 
the kite. Maximum attention should be paid to this stage because preventing potential injuries depends on how the kite and the lines are prepared;

3. self-rescue technique - the participant learns to use the control bar and the couplingdecoupling system of the kite. It is essential for the learner to understand all its safety systems in order to properly use them if needed;

4. bar and safety systems - the participant learns to position the kite so that it becomes a sail that allows navigation to shore. This manoeuvre is important because it is used whenever the learner is in a difficult situation or has to return to shore - there are problems with the equipment or the wind has decreased or increased in intensity and no longer allows the safe practice of kitesurfing;

5. kite control - is one of the most important learning steps because kitesurfing involves kite control in a proportion of $80 \%$. Participants need to learn kite control with both hands and one hand as well. This will make it easier for them to control the kite but also the board when entering the water;

6. body drag upwind - is the first learning step performed in the water and involves using the kite to move on the water in a predetermined direction without the board;

7. power stroke - the participant learns how to use the kite's power to lift above the water. This is the stage where the position on the board is learned;

8. assisted water start - the impulses of lifting the board on the water are used, which is followed by controlled walking with the help of the instructor;

9. water start solo - the learner tries to sail alone, receiving helpful instructions from the shore;

10. ride downwind - the participant tries to sail alone and safely into the wind; the instructor guides and assists the learner from the shore. After each ride downwind, the participant must return to the beach;

11. ride upwind - is the stage that makes the transition from beginner to advanced level. It basically means sailing against the wind;

12. transitions - when both directions of travel are mastered, the participant learns the transitions that will allow the change of direction.

The safety of each participant is a priority throughout the period focused on learning the kitesurfing technique (Wiesner \& Kunysz, 2018), but also beyond it. However, the risk of accidents and injuries is high (Nickel et al., 2004, Petersen et al., 2005, Pikora et al., 2011) and constantly present, as in all extreme sports. Despite this, both young people and adults and seniors (Immonen et al., 2018; Baumbach et al., 2018) choose to accept the challenge and venture into the open sea to experience strong sensations.

But not merely the pleasure of adrenaline is the reason why kitesurfing is practised. It is worth mentioning the many benefits offered by this sport to the whole body. Thus, there are studies that have demonstrated the effects of kitesurfing on the cardiovascular (Bourgois et al., 2014), respiratory and muscular systems but also on the mental training of athletes (Lundgren et al., 2011), with a significant impact on their cognitive abilities and emotional areas. All these are permanently in close connection and are directly influenced by the environmental factors, which play a major role in the practice of this sport. 


\section{Conclusion}

Although kitesurfing seems to be a sport accessible to all ages and training levels, it requires good fitness and a proper understanding of the equipment and environmental factors, which definitely influence its practice. The desire to sail faster, coupled with the need for adrenaline and the pleasure of practising new sports, have to be accompanied by appropriate equipment (Lundgren et al., 2012), which helps the athlete to manage and control the risk of kitesurfing injuries. According to Lundgren et al. (2011), education and improved design of the equipment are crucial to increase safety for kiteboarders.

Kitesurfing is considered a high-risk sport because the possibility of serious accidents can occur at any time during practice. However, studies show that the injury rate of kitesurfing is in the range of other popular (contact) sports, most injuries being relatively mild (van Bergen et al., 2020).

On the other hand, kitesurfing offers participants the opportunity to become aware of their own limits and to combine sport and passion during a unique movement experience that cannot be achieved by practising another sport.

\section{Authors' Contributions}

All authors have equally contributed to this paper and should be considered as main authors.

\section{Acknowledgements}

The authors thank the kitesurfers who helped them to accomplish this paper.

\section{References}

Baumbach, S. F, Stawinski, T., Schmitz, D., Schoeneberg, C., Jaeger, M., Wedemeyer, C., \& Kauther, M. (2018). Influence of kitesurf equipment on injury rates. Journal of Sports Medicine and Physical Fitness, 58(10), 1482-1489.

DOI: $10.23736 / \mathrm{S} 0022-4707.17 .07152-3$

Bourgois, J. G., Boone, J., Callewaert, M., Tipton, M. J., \& Tallir, I. B. (2014). Biomechanical and physiological demands of kitesurfing and epidemiology of injury among kitesurfers. Sports Medicine, 44(1), 55-66. https://doi.org/10.1007/s40279-013-0103-4

Brymer, E., Downey, G., \& Gray, T. (2009). Extreme sports as a precursor to environmental sustainability. Journal of Sport \& Tourism, 14(2-3), 193-204. https://doi.org/10.1080/14775080902965223

Brymer, E., \& Feletti, F. (2020). Beyond risk: the importance of adventure in the everyday life of young people. Annals of Leisure Research, 23(3), 429-446.

DOI 10.1080/11745398.2019.1659837

Caraballo, I., González-Montesinos, J. L., Casado-Rodríguez, F., \& Gutierrez-Manzanedo, J. V. (2021). Performance analysis in Olympic sailors of the Formula Kite class using GPS. Sensors, 21(2): 574. https://doi.org/10.3390/s21020574

Castro Maqueda, G., Gutierrez-Manzanedo, J. V., Gonzalez-Montesinos, J. L., Vaz Pardal, C. Rivas Ruiz, F., \& Troya Martin, M. (2020). Sun exposure and photoprotection: Habits, knowledge and attitudes among elite kitesurfers. Journal of Cancer Education. 
https://doi.org/10.1007/s13187-020-01838-7

Cho, S. M., Kang, J. H., \& Koh, A. R. (2010). Characteristics of extreme sports participants' lifestyles and sportswear benefits sought - A comparison between participants of extreme and traditional sports. Journal of the Korean Society of Clothing and Textiles, 34(12), 20512061. https://doi.org/10.5850/JKSCT.2010.34.12.2051

Clayton, J. (2016). Kitesurfing for beginners: A guide to kitesurfing equipment. https://mpora.com/windsurfing-kitesurfing/kitesurfing-equipment-beginners-guideessential-gear/

Currer, I. (2002). Kitesurfing - The complete guide. Northern Paragliding Ltd.

Duong, T. (2014). Extreme sports essay. https://www.scribd.com/document/237010899/Extreme-Sports-Essay

Exadaktylos, A. K., Sclabas, G. M., Blake, I., Swemmer, K., McCormick, G., \& Erasmus, P. (2005). The kick with the kite: an analysis of kite surfing related off shore rescue missions in Cape Town, South Africa. British Journal of Sports Medicine, 39(5), e26. DOI: $10.1136 / \mathrm{bjsm} .2004 .014795$

Fadda, N. (2019). Tourism from Water Boardsports: Evidence from the Emerging Destination of Sardinia. Journal of the Knowledge Economy, 10(4), 1720-1737.

DOI: $10.1007 / \mathrm{s} 13132-019-0587-8$

Fandom. (2018). Extreme sport. https://ultimatepopculture.fandom.com/wiki/Extreme_sport

Forsyth, J. R., Riddiford-Harland, D. L., Whitting, J. W., Sheppard, J. M., \& Steele, J. R. (2020). Essential Skills for Superior Wave-Riding Performance: A Systematic Review. Journal of Strength and Conditioning Research, 34(10), 3003-3011. DOI: $10.1519 /$ JSC.0000000000003402

Fruehauf, A., Zenzmaier, J., \& Kopp, M. (2020). Does age matter? A qualitative comparison of motives and aspects of risk in adolescent and adult freeriders. Journal of Sports Science and Medicine, 19(1), 112-120. PMID: 32132834

Gratwick, A. (2015). The kiteboarding manual - The essential guide for beginners and improvers. Adlard Coles Nautical.

Grzeczka, A., Kohut, P., Klaczynski, M., Wittbrodt, E., \& Uhl, T. (2016). Motion analysis of a kitesurfer employing a vision-based measurement system. Journal of Vibroengineering, 18(3), 1884-1892. https://doi.org/10.21595/jve.2016.17099

Hapgood, A. (2014). Kiteboarding: Where it's at... Adlard Coles Nautical.

Immonen, T., Brymer, E., Davids, K., Liukkonen, J., \& Jaakkola, T. (2018). An ecological conceptualization of extreme sports. Frontiers in Psychology, 9: 1274. https://doi.org/10.3389/fpsyg.2018.01274

Keane, M., Eastman, J. K., \& Iyer, R. (2020). Predicting adventure seeking of young adults: The role of risk, innovativeness and status consumption. Sport Management Review, 23(5), 952-963. https://doi.org/10.1016/j.smr.2019.12.009

Kupciw, D., \& MacGregor, A. (2012). High-risk sport research. The Sport and Exercise Scientist, 31, 28-29. https://psychologsportu.files.wordpress.com/2012/04/28-291.pdf

Leeuwerke, S.J.G., Sinnathamby, M. \& Zellweger, R. (2016). Kitesurfing-playing with water or with fire? Medical Journal of Australia, 204(8):301. DOI 10.5694/mja15.01130

Lundgren, L., Bligard, L.O., Brorsson, S., \& Osvalder, A.L. (2011). Implementation of usability analysis to detect problems in the management of kitesurfing equipment. Procedia Engineering, 13, 525-530. https://doi.org/10.1016/j.proeng.2011.05.125

Lundgren, L., Brorsson, S., Hilliges, M., \& Osvalder, A.L. (2011). Sport performance and perceived musculoskeletal stress, pain and discomfort in kitesurfing. International Journal of Performance Analysis in Sport, 11(1), 142-158. https://doi.org/10.1080/24748668.2011.11868536 
Lundgren, L., Brorsson, S., \& Osvalder, A. L. (2012). Comfort aspects important for the performance and safety of kitesurfing. Work. A Journal of Prevention Assessment \& Rehabilitation, 41(Supplement: 1), 1221-1225. DOI: 10.3233/WOR-2012-0306-1221

Marinescu, Gh., Tudor, V., Mujea, A.-M., \& Băisan, C. (2014). The improvement of strength in mentally disabled pupils through the use of differentiated instruction in the physical education lesson. Procedia - Social and Behavioral Sciences, 117, 529-533. https://doi.org/10.1016/j.sbspro.2014.02.257

Mexican Caribbean Kitesurf. (2017). 14 steps to learn kitesurfing. http://www.mexicancaribbeankitesurf.com/14-steps-to-learn-kitesurfing

Morvan, J. B., Riviere, D., Vatin, L., Joubert, C., Bousquet, F., \& Cathelinaud, O. (2018). Kitesurfing and Cranial Trauma with Frontal Sinus Fracture. Current Sports Medicine Reports, 17(1), 23-25. DOI: 10.1249/JSR.0000000000000443

Nebas, T., \& Heller, B. (2014). A smartphone based system for kite and board measurements in kitesurfing. Engineering of Sport 10, Procedia Engineering, 72, 477-482. DOI 10.1016/j.proeng.2014.06.084

Nickel, C., Zernial, O., Musahl, V., Hansen, U., Zantop, T., \& Petersen, W. (2004). A prospective study of kitesurfing injuries. The American Journal of Sports Medicine, 32(4), 921-927. https://doi.org/10.1177/0363546503262162

Pikora, T. J., Braham, R., Hill, C., \& Mills, C. (2011). Wet and wild: results from a pilot study assessing injuries among recreational water users in Western Australia. International Journal of Injury Control and Safety Promotion, 18(2), 119-126. DOI 10.1080/17457300.2010.540333

Petersen, W., Hansen, U., Zernial, O., Nickel, C., \& Prymka, M. (2002). Mechanisms and prevention of kitesurfing injuries. Sportverletzung-Sportschaden, 16(3), 115-121. DOI 10.1055/s-2002-34751

Petersen, W. N., Nickel, C., Zantop, T., \& Zernial, O. (2005). Kitesurfing injuries. A young sport. Orthopade, 34(5), 419-425. https://doi.org/10.1007/s00132-005-0792-y

Știrbu, C. I., \& Știrbu, C. M. (2014). Extreme sports - forms of physical exercise in the nature. Gymnasium - Scientific Journal of Education, Sports and Health, 1(XV), 1-22. http://www.gymnasium.ub.ro/index.php/journal/article/view/194

Tomlinson, J., \& Leigh, E. (2004). Extreme sports: In search of the ultimate thrill. Firefly Books Ltd.

Ultimate France. (2018). Mondial du Vent - Kiteboarding. https://www.ultimatefrance.com/event/mondial-du-vent

van Bergen, C. J. A., Commandeur, J. P., Weber, R. I. K., Haverkamp, D., \& Breederveld, R. S. (2016). Windsurfing vs kitesurfing: Injuries at the North Sea over a 2-year period. World Journal of Orthopedics, 7(12), 814-820. DOI 10.5312/wjo.v7.i12.814

van Bergen, C.J.A., Weber, R.I., Kraal, T., Kerkhoffs, G.M., \& Haverkamp, D. (2020). Kitesurf injury trauma evaluation study: A prospective cohort study evaluating kitesurf injuries. World Journal of Orthopedics, 11(4), 243-251. https://doi.org/10.5312/wjo.v11.i4.243

White Cap Windsurfing. (2020). Kitesurfing equipment. https://whitecapwindsurfing.com/kitesurfing-equipment/

Wiesner, W., \& Kunysz, P. (2018). Risk management in kitesurfing as a basic condition of effective learning and safe swimming. Polish Hyperbaric Research, 64(3), 55-67. https://doi.org/10.2478/phr-2018-0019 